\title{
Respiratory Morbidities in Preterm Neonates During the First Year of Life: A Prospective Observational Study
}

\author{
Jenisha Jain, Lakshmi Venugopal' ${ }^{1}$, R. Shanmughsundaram ${ }^{1}$ \\ Choithram Hospital and Research Centre, Indore, Madhya Pradesh, 'Department of Neonatology, Mehta Multispeciality Hospitals India Pvt. Ltd, Chennai, Tamil Nadu, \\ India
}

\section{Abstract}

Background: Infants born preterm develop numerous short- and long-term respiratory morbidities. However, there are scanty data available from India. Aims: The study was conducted to determine the incidence of hospitalization due to respiratory morbidities during the $1^{\text {st }}$ year of life in preterm neonates ( $<37$ completed weeks). The secondary aim was to determine the impact of respiratory morbidity on growth and need for nebulization. Patients and Methods: This prospective study was conducted in a level III neonatal intensive care unit. Data regarding maternal and neonatal history and examination were collected in the study proforma. Follow-up was done at predetermined intervals, and details of subsequent outpatient and inpatient treatments were recorded. Statistical analysis - Chi-square test/Fisher's exact test, unpaired $t$-test, and multivariate logistic regression were used for statistical analysis. $P<0.05$ was considered as statistically significant. Results: Three hundred and forty-four infants (192 - male and 121 - inborn) were included. Fifty-eight (16.8\%) infants were readmitted - $84 \%$ bronchiolitis, $12 \%$ pneumonia, and $27.5 \%$ as wheeze-associated lower respiratory tract infection. On multivariate analysis, growth status at birth, presence of hemodynamically significant patent ductus arteriosus (PDA), lower socioeconomic status (SES), and lack of exclusive breastfeeding were associated with risk of readmission. 12.2\% (42/344) of the admitted preterm neonates needed nebulization with bronchodilators during follow-up. Growth was hampered in those requiring readmissions. Conclusion: $16.8 \%$ of the preterm neonates were admitted for respiratory morbidities at 1-year follow-up. Small for gestational age, presence of hemodynamically significant PDA needing medical closure, lack of exclusive breastfeeding for 6 months, and lower SES were risk factors for respiratory morbidity in infancy.

Keywords: Follow up, infancy, preterm infants, respiratory morbidities

\section{INTRODUCTION}

Prematurity is an important early life challenge that has adverse consequences on health in later life. ${ }^{[1]}$ India has the highest number of preterm births in the world. ${ }^{[2]}$ Most preterm neonates require ventilatory support and oxygen supplementation, and many of them go on to develop chronic lung disease. ${ }^{[3]}$ In India, there are scanty data regarding long-term respiratory outcomes of such babies. ${ }^{[4]}$

Thus, the present study was undertaken to determine the incidence of respiratory morbidities during the $1^{\text {st }}$ year of life in preterm neonates, born at $<37$ weeks. Moreover, we tried to determine the neonatal risk factors associated with respiratory morbidities.

\section{Patients and Methods}

This prospective, observational study was done between May 2016 and May 2018 at a tertiary level III neonatal intensive care

\begin{tabular}{|l|l|}
\hline \multicolumn{2}{|c|}{ Access this article online } \\
\hline Quick Response Code: & Website: \\
\hline & www.ijrc.in \\
\cline { 2 - 2 } & \\
\hline
\end{tabular}

unit (NICU). The study was approved by the Institutional Ethics committee. The study was performed with ethical standards which confirm with the Helsinki Declaration of 1975, as revised in 2000 and 2008 confirming human and animal rights.

We included all preterm neonates with gestational age $<37$ completed weeks. Neonates with major congenital malformations, congenital heart disease, chromosomal abnormalities, primary or secondary immunodeficiency, and infants whose parents did not give consent for participation were excluded from the study.

Address for correspondence: Dr. Jenisha Jain, 297, Indrapuri, Indore, Madhya Pradesh, India. E-mail: tojenisha@gmail.com

This is an open access journal, and articles are distributed under the terms of the Creative Commons Attribution-NonCommercial-ShareAlike 4.0 License, which allows others to remix, tweak, and build upon the work non-commercially, as long as appropriate credit is given and the new creations are licensed under the identical terms.

For reprints contact: WKHLRPMedknow_reprints@wolterskluwer.com

How to cite this article: Jain J, Venugopal L, Shanmughsundaram R. Respiratory morbidities in preterm neonates during the first year of life: A prospective observational study. Indian J Respir Care 2021;10:70-5.

Received: $22-08-2020$ Published: $31-01-2021$
Accepted: 04-09-2020 
The sample size was calculated based on the primary outcome variable: hospitalization $>24 \mathrm{~h}$. The expected frequency was estimated to be around $25 \%$. With alpha $=0.05$, absolute precision $5 \%$, and expected dropout of $20 \%$, the corrected sample size was 360 infants.

Data were collected and entered in a predesigned proforma. Variables relating to mother noted were age, parity, date of last menstruation, duration of gestation assessed by obstetric ultrasound, type of delivery, maternal socioeconomic status (SES) (as per modified Kuppuswamy scale), maternal history of asthma/allergy, complete course of antenatal steroids, magnesium sulfate, obstetric complications such as pregnancy-induced hypertension $(\mathrm{PIH})$, preterm premature rupture of the membranes (PPROM), chorioamnionitis, multiple pregnancy, and diabetes mellitus.

The following variables were recorded with respect to the newborn:birth weight, sex, gestational age, APGAR score, duration of oxygen, duration of mechanical ventilation, duration of continuous positive airway pressure (CPAP), duration of heated, humidified high flow nasal cannula (HHHFNC). Presence of surfactant associated comorbidities: apnea, respiratory distress syndrome, transient tachypnea of the newborn (TTNB), pneumonia, air leak syndromes, persistent pulmonary hypertension, hemodynamically significant patent ductus arteriosus(PDA), bronchopulmonary dysplasia were also recorded.

Other co-morbidities such as intraventricular hemorrhage (IVH), sepsis, necrotizing enterocolitis, shock requiring inotropes, anemia needing transfusion, retinopathy of prematurity needing treatment, duration of stay, and outcome were also recorded on a predesigned proforma..

\section{Definitions used}

Gestational age was estimated from the $1^{\text {st }}$ day of the last menstrual period or, when the date was uncertain, by obstetric ultrasound performed by 20 weeks of gestation or using new Ballard scores at birth if neither of the two data were available.

Weight was classified as appropriate, small, or large for gestational as per the criteria used by Fenton and Kim. ${ }^{[5]}$

Apnea, ${ }^{[6]}$ respiratory distress syndrome, ${ }^{[7]}$ sepsis,${ }^{[8]}$ persistent pulmonary hypertension, ${ }^{[9]}$ meconium aspiration syndrome ${ }^{[10]}$ pulmonary hemorrhage, ${ }^{[11]}$ and bronchopulmonary dysplasia ${ }^{[12]}$ were defined as per standard definitions in the literature.

The types of respiratory morbidities were defined as follows:

a. Bronchiolitis: A constellation of clinical symptoms and signs including a viral upper respiratory prodrome, followed by increased respiratory effort and wheezing in young infants ${ }^{[13]}$

b. Pneumonia: presence of fever, tachypnea, chest retractions or inability to drink or central cyanosis along with chest $\mathrm{X}$-ray changes

c. Wheeze-associated lower respiratory tract infection was defined as tachypnea, dyspnea, and wheezing on auscultation with or without fever.
Criteria for admission for respiratory problem during infancy were at the discretion of the treating physician and included severity of respiratory distress and need for intravenous fluid and antibiotics. The diagnoses of respiratory morbidities were made by the treating pediatrician clinically, along with radiological and other laboratory supports.

The study included five follow-up visits at the study center at 1, 3, 6, 9, and 12 months. All the details regarding growth, number of nebulization, hospitalizations, and other variables were recorded by the principal investigator (JC). Details of all respiratory morbidities were entered at follow-up based on the available records of discharge summary and treatment records.

Statistical analysis was done using SPSS Statistics for Windows, version 18.0 (SPSS Inc., Chicago, Ill., USA). Data which followed normal distribution and mean \pm standard deviation were calculated, and for skewed data, median and interquartile range (IQR) were calculated. Chi-square test, Fisher's exact test, and unpaired $t$-tests were used. The odds ratio (OR) was calculated. Categorical factors significant by univariate analysis were included in multivariate logistic regression by enter method. $P<0.05$ was considered as statistically significant.

\section{RESULTS}

A total of 344 infants were included in the analysis [Figure 1]. The mean gestational age and birth weight were $32.7 \pm 2.5$ weeks and $766.96 \pm 591.42 \mathrm{~g}$, respectively. There were 192 male babies $(55 \%)$. Nearly $35 \%(n=121)$ of the patients were inborn. Of these, $58(16.8 \%)$ infants were readmitted during the $1^{\text {st }}$ year of life. Fifty infants were admitted at the study center, and eight infants were admitted at outside hospitals.

\section{Maternal characteristics}

Three-fourths of the conceptions were spontaneous, while the others required assisted reproduction methods. PIH was noted in one-fifth of the cases and diabetes and hypothyroidism in $7.8 \%$ of

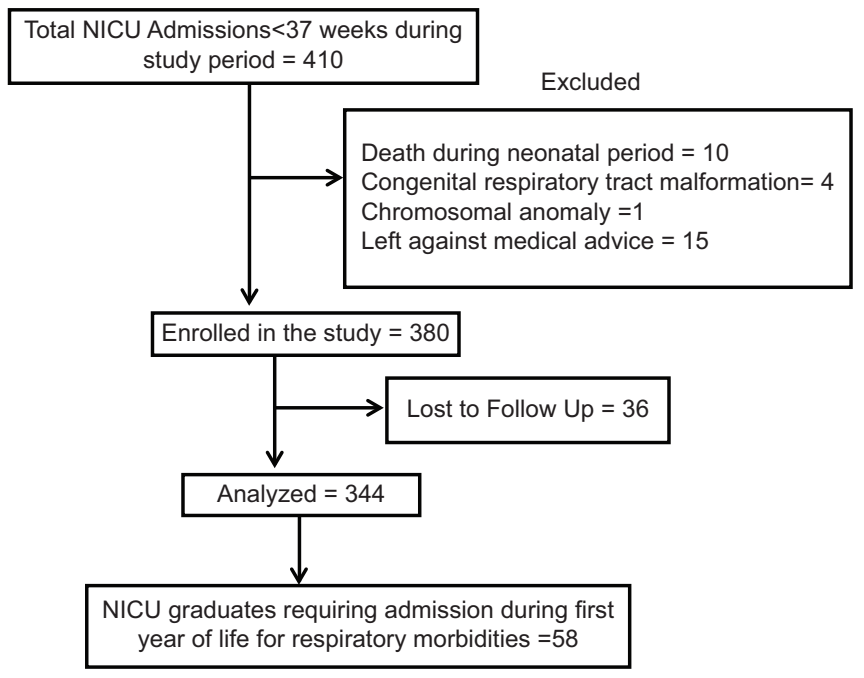

Figure 1: Study methodology 
the cases. Eleven percent of the mothers suffered from PPROM, and $47.3 \%$ had been administered antenatal steroids. The mean maternal ages for neonates born at $<28$ weeks, 28-34 weeks, and $34-36$ weeks were $29.45 \pm 5,28.85 \pm 5$, and $28.85 \pm 5.2$ years, respectively. There were $14.5 \%$ of the mothers who belonged to SES class 2, 42.4\% belonged to SES class 3, 36.9\% belonged to SES class 4 , and $6.1 \%$ belonged to SES class 5 .

\section{Neonatal characteristics}

There were $11(3.19 \%)$ patients $<28$ weeks of gestation, $235(68.4 \%)$ patients were between 28 and 33 weeks, and $34(9.8 \%)$ patients were between 34 weeks and 36 completed weeks of gestation at birth. Thirty-two patients $(9.3 \%)$ weighed $<1000 \mathrm{~g}, 86(25 \%)$ patients were between 1001 and $1500 \mathrm{~g}, 118(34.3 \%)$ patients were between 1501 and $2000 \mathrm{~g}$, and $108(31.3 \%)$ patients weighed $>2000 \mathrm{~g}$ at birth. $89.2 \%(n=307)$ were appropriate for gestational age, $9.8 \%(n=34)$ were small for gestational age, and $3(0.8 \%)$ were large for gestational age at birth. $54.6 \%(n=188)$ were delivered by emergency cesarean section, 85 (24.7\%) were delivered by elective cesarean section, and $20.6 \%(n=71)$ were delivered by vaginal route. Only a few babies needed resuscitation at birth $(8.4 \%)$. During the neonatal period, TTNB was diagnosed in 110 (319\%) neonates, respiratory distress syndrome was diagnosed in $85(24.7 \%)$ neonates, and persistent pulmonary hypertension and meconium aspiration syndrome each were noted in $3(0.8 \%)$ patients, respectively. Pneumothorax was also diagnosed in $3(0.8 \%)$ patients, and bronchopulmonary dysplasia was diagnosed in $7(2 \%)$ patients. Apnea was observed in $9(2.6 \%)$ patients. Shock requiring inotropic support was noticed in $24(6.9 \%)$ patients. Necrotizing enterocolitis was observed in $14(4 \%)$ patients. IVH was observed in $4(1.1 \%)$ patients, $2(0.5 \%)$ patients were diagnosed as Grade I IVH, $1(0.25 \%)$ patient had Grade 2 IVH, and $1(0.25 \%)$ patient had Grade 3 IVH. Clinical sepsis $(38,11 \%)$ and hemodynamically significant ductus requiring medical closure $(34,9.8 \%)$ were the other major complications. The gestational age-wise breakup of respiratory diagnosis and management is shown in Table 1.

\section{Duration of respiratory support during neonatal period}

The median duration of mechanical ventilation was $39 \mathrm{~h}$ (IQR: 20-71 h). For CPAP and HHHFNC, it was $38.5 \mathrm{~h}$ and $44 \mathrm{~h}$, respectively. The median duration of oxygen therapy alone was $72.5 \mathrm{~h}$.

\section{Baseline characteristics of infants requiring readmission $(n=58)$}

Majority were male babies $(37,63.8 \%)$, born at $<33$ weeks' gestation $(49,84.5 \%)$, and outborn, and $50 \%$ had birth weight $<1500$ g. Forty-six (79.3\%) were admitted for one time, $7(12 \%)$ were admitted twice, and $5(8.6 \%)$ were admitted $\geq 3$ times during infancy. The diagnosis at readmissions is shown in Table 2.

On univariate analysis [Table 3], gestational age, growth status at birth, birth weight, place of delivery (inborn/outborn), need for surfactant, APGAR $<7$ at $5 \mathrm{~min}$, and presence of hemodynamically significant PDA were significantly associated with risk of readmission due to respiratory problem. Among environmental factors, lower SES and lack of exclusive breastfeeding for the first 6 months of life were associated with a significantly higher risk of readmission. Neonates needing invasive or noninvasive ventilation at birth were at higher risk of readmission due to respiratory illness during infancy (OR: 2.41 [95\% confidence interval (CI): 1.36-4.29]).

On gestation-wise analysis, neonates in the gestation age category 28-33 weeks who required invasive or noninvasive respiratory support at birth were at significantly higher risk of readmission (OR: 2.2 [95\% CI: 1.14-4.3]).

Using entry method, the logistic regression model revealed that growth status at birth (adjusted OR [AOR]: 3.68), hemodynamically significant PDA $(\mathrm{AOR}=5.0)$, lower SES (AOR = 13.5), and lack of exclusive breastfeeding for 6 months $(A O R=4.7)$ were significantly associated with hospital readmission among infants [Table 4].

\section{Discussion}

In the current study, recruitment of all neonates born $<37$ completed weeks of gestation admitted in a tertiary level NICU was done. Various studies addressing this issue in the past have used variable cutoffs for gestational age. ${ }^{[14-16]}$ In our study population, a total of $58(16.8 \%)$ neonates required readmissions during the $1^{\text {st }}$ year of life for respiratory morbidities. The incidence was similar to other studies. ${ }^{[15,16]}$ Majority of the patients $(79.3 \%, 46)$ required single hospital

\begin{tabular}{|c|c|c|c|}
\hline & $\begin{array}{c}<28 \text { weeks } \\
(n=11), n(\%)\end{array}$ & $\begin{array}{c}28-33 \text { weeks } \\
(n=235), n(\%)\end{array}$ & $\begin{array}{c}34-36 \text { weeks } \\
(n=98), n(\%)\end{array}$ \\
\hline TTNB $(n=110)$ & $3(27.2)$ & $73(31)$ & $34(34.6)$ \\
\hline $\operatorname{RDS}(n=85)$ & $9(81.8)$ & $68(28.9)$ & $9(9.1)$ \\
\hline PPHN & 0 & 0 & $3(3.06)$ \\
\hline Meconium aspiration syndrome & 0 & 0 & $3(3.06)$ \\
\hline Need for surfactant & $9(81.8)$ & $61(25.9)$ & $12(12.2)$ \\
\hline Need for invasive or noninvasive ventilation at birth $(n=134)$ & $9(81.8)$ & $105(44.6)$ & $20(20.4)$ \\
\hline
\end{tabular}

TTNB: Transient tachypnea of the newborn, RDS: Respiratory distress syndrome, PPHN: Persistent pulmonary hypertension of the newborn 


\begin{tabular}{|c|c|c|c|c|}
\hline Diagnosis $(n=58)$ & $0-3$ months $(n=21 ; 36.2 \%)$ & $3-6$ months $(n=14 ; 24.1 \%)$ & $6-9$ months $(n=20 ; 34.4 \%)$ & 9-12 months ( $n=17 ; 29.3 \%)$ \\
\hline Bronchiolitis & $18(85.7)$ & $12(85.7)$ & $12(60)$ & $7(41.1)$ \\
\hline Pneumonia & $3(14.2)$ & $2(14.2)$ & $1(5)$ & $1(5.8)$ \\
\hline WALRI & $0(0)$ & $0(0)$ & $7(35)$ & $9(52.9)$ \\
\hline
\end{tabular}

WALRI: Wheeze-associated lower respiratory tract infection

Table 3: Univariate analysis for risk factors of readmission

\begin{tabular}{|c|c|c|c|}
\hline & Readmitted $(n=58), n$ (\%) & Not admitted $(n=286), n(\%)$ & $P$ \\
\hline \multicolumn{4}{|c|}{ Maternal and neonatal characteristics } \\
\hline Male & $37(63.8)$ & $155(54.2)$ & 0.18 \\
\hline AGA & $46(79.3)$ & $267(93.3)$ & $<0.0001$ \\
\hline SGA & $11(18.9)$ & $17(6)$ & \\
\hline LGA & $1(1.7)$ & $2(0.6)$ & \\
\hline \multicolumn{4}{|l|}{ Type of delivery } \\
\hline Vaginal delivery & $11(19)$ & $60(20.9)$ & 0.61 \\
\hline Elective LSCS & $12(21)$ & $73(25.5)$ & \\
\hline Emergency LSCS & $35(60)$ & $153(53.6)$ & \\
\hline \multicolumn{4}{|l|}{ Gestational age (weeks) } \\
\hline$<28$ & $4(6.9)$ & $7(2.4)$ & 0.018 \\
\hline $28-33$ & $45(77.6)$ & $190(66.4)$ & \\
\hline $34-36$ & $9(15.7)$ & $89(31.2)$ & \\
\hline \multicolumn{4}{|l|}{ Type of conception } \\
\hline Spontaneous & $46(79)$ & $212(74.10$ & NA \\
\hline IVF & $12(21)$ & $72(25.2)$ & \\
\hline Ovulation drugs & $0(0)$ & $2(0.7)$ & \\
\hline PPROM $<12$ h & $52(89.6)$ & $254(88.8)$ & 0.85 \\
\hline Complete ANCS received & $32(55.2)$ & $131(45.8)$ & 0.14 \\
\hline \multicolumn{4}{|l|}{ Birth weight (g) } \\
\hline$<1000$ & $11(19)$ & $21(7.3)$ & 0.006 \\
\hline $1001-1500$ & $18(31)$ & $68(23.7)$ & \\
\hline $1501-2000$ & $19(32.7)$ & $99(34.6)$ & \\
\hline$>2000$ & $10(17.3)$ & $98(34.6)$ & \\
\hline Apgar $<7$ at $5 \mathrm{~min}$ & $17(29.3)$ & $48(16.7)$ & 0.02 \\
\hline Need for oxygen support $\leq 72 \mathrm{~h}$ & $54(93.1)$ & $272(95)$ & 0.55 \\
\hline Bronchopulmonary dysplasia & $3(5.2)$ & $4(1.3)$ & 0.06 \\
\hline Hemodynamically significant PDA needing medical closure & $19(32.75)$ & $15(5.2)$ & $<0.0001$ \\
\hline Twins & $13(22.4)$ & $85(29.7)$ & 0.26 \\
\hline IB & $18(31)$ & $103(36)$ & 0.46 \\
\hline Need for surfactant & $24(42)$ & $59(20.6)$ & 0.0005 \\
\hline \multicolumn{4}{|c|}{ Environmental factors } \\
\hline \multicolumn{4}{|l|}{ Socioeconomic status } \\
\hline 2 & $8(13.7)$ & $3(1)$ & $<0.0001$ \\
\hline 3 & $36(62))$ & $39(134.6)$ & \\
\hline 4 & $14(24.3)$ & $223(77.8)$ & \\
\hline 5 & $0(0)$ & $21(7.3)$ & \\
\hline Exclusive breastfeeding for 6 months & $24(42)$ & $245(85.6)$ & $<0.0001$ \\
\hline
\end{tabular}

admission, $12 \%^{[7]}$ required admission twice, and $8.6 \%{ }^{[5]}$ required three or more admissions. This aspect of readmission is not reported in other studies. ${ }^{[14-16]}$ Among patients who got readmitted, bronchiolitis was the most common clinical presentation, followed by wheeze-associated lower respiratory tract infection (WALRI) and pneumonia, respectively. This is not completely comparable to other studies due to differences in study design, methodology, and definitions used. ${ }^{[14-17]}$ The most common age of presentation for bronchiolitis was $<6$ months, whereas WALRI was diagnosed after 6 months of age. 
Jain, et al:: Respiratory morbidities in preterm neonates

\begin{tabular}{|c|c|c|c|c|}
\hline Variables & Unadjusted OR & Adjusted OR & 95\% CI for adjusted OR & $P$ \\
\hline \multicolumn{5}{|l|}{ Gestational age } \\
\hline Up to 32 weeks & 2.46 & 0.888 & $0.33-2.35$ & 0.811 \\
\hline \multicolumn{5}{|l|}{ Birth weight } \\
\hline Up to $1500 \mathrm{~g}$ & 2.23 & 1.200 & $0.47-3.03$ & 0.700 \\
\hline \multicolumn{5}{|l|}{ Growth status } \\
\hline SGA & 6.56 & 3.680 & $2.1-8.6$ & 0.02 \\
\hline \multicolumn{5}{|c|}{ Apgar score at $5 \mathrm{~min}$} \\
\hline Up to 7 & 2.05 & 1.266 & $0.47-3.3$ & 0.638 \\
\hline \multicolumn{5}{|c|}{ Surfactant therapy during neonatal period } \\
\hline Yes & 2.71 & 0.713 & $0.22-2.27$ & 0.568 \\
\hline \multicolumn{5}{|c|}{$\begin{array}{l}\text { Hemodynamically significant PDA needing medical } \\
\text { closure during neonatal period }\end{array}$} \\
\hline Yes & 8.8 & 5.078 & $1.4-17.9$ & 0.012 \\
\hline \multicolumn{5}{|c|}{ Need for invasive or noninvasive ventilation at birth } \\
\hline Yes & 2.41 & 1.020 & $0.38-2.7$ & 0.968 \\
\hline \multicolumn{5}{|c|}{ Exclusive breastfeeding till 6 months of age } \\
\hline No & 8.46 & 4.780 & $2.2-10.2$ & 0.000 \\
\hline \multicolumn{5}{|c|}{ Socio economic status } \\
\hline Up to Class 3 & 18.2 & 13.4 & $6.3-28.5$ & 0.000 \\
\hline
\end{tabular}

OR: Odds ratio, CI: Confidence interval, PDA: Patent ductus arteriosus, SGA: Small-for-gestational age

The neonatal risk factors significantly associated with increased risk of readmission included gestational age $<32$ weeks, birth weight $<1500 \mathrm{~g}$, APGAR score $<7$ at $5 \mathrm{~min}$, need for surfactant therapy at birth, presence of hemodynamically significant PDA, and need for respiratory support at birth. Gestational age and birth weight have been reported to be associated with higher readmissions in a few studies. ${ }^{[14,18]}$ Similarly, earlier studies have reported that low APGAR score is significantly associated with risk of rehospitalization during the $1^{\text {st }}$ year of life, a finding similar to previous studies. ${ }^{[16]}$ Its significance can be explained by the presence of hypoxic lung injury at birth or need for longer respiratory support at birth. We found a significant association between presence of hemodynamically PDA at birth and risk of readmission during infancy. Pulmonary injury induced by pulmonary edema as a result of PDA may result in a higher need for respiratory support at birth. However, the duration of exposure to PDA was not studied in the present study. Surfactant therapy was required by $82(23.8 \%)$ neonates. Although surfactant use was determined as a risk factor on univariate analysis, multivariate analysis did not find it to be a significant factor predicting the need for readmission. A recent meta-analysis of the neonatal respiratory outcomes between the pre- and the postsurfactant era found better FEV1 at school age and early adulthood of subjects born prematurely in the postsurfactant era, especially those with BPD. ${ }^{[19]}$ In a study by Hong et al., neonatal exogenous surfactant administration reduced respiratory hospitalization within the first 3 years postdischarge. ${ }^{[20]}$

Requirement of invasive or noninvasive ventilation at birth was a significant risk factor (relative risk: 2.41 [95\% CI: 1.36-4.29]) for readmission, a finding similar to previous reports. ${ }^{[14,15]}$ In gestation-wise stratification, nine babies $<28$ weeks' gestational age $(81.8 \%)$ required invasive or noninvasive ventilation at birth. Of these 9 cases, 4 (44.44\%) were rehospitalized for respiratory morbidities. However, due to the small sample size in this subclass, the results were not statistically significant (OR: 4 [95\% CI: $0.5-108]$ ). The rate of rehospitalization in our cases (44.4\%) was similar to the reported literature (approximately 50\%). ${ }^{[21-23]}$ In those born at 28-33 weeks of gestation, need for invasive or noninvasive ventilation at birth was significantly associated with hospital readmission. This is similar to other studies in this gestational age category. ${ }^{[24]}$ In newborns between 34 and 36 weeks of gestation, need for ventilation was not significantly associated with the risk of rehospitalization (OR: 1.21 [95\% CI: 0.21-5.8]). However, the readmission rates were nearly double of the previous studies. ${ }^{[25]}$ This suggests that even this "supposedly mature" group of neonates is vulnerable to short- and long-term respiratory morbidities.

We noted that infants belonging to lower socioeconomic class had significantly more risk of readmissions, a finding similar to previous studies. ${ }^{[21,23]}$ This may be explained by poor hygienic conditions and reduced access to health services in this socioeconomic group. We have found a significantly increased risk of readmission in infants who were not on exclusive breastfeeding, which is in accordance with other studies by Oddy et al., ${ }^{[26]}$ Kaur et al., ${ }^{[27]}$ and Tromp et al. ${ }^{[28]}$ Breast milk has numerous benefits including immunological benefits which are likely to reduce respiratory infections.

\section{Limitations}

Risk factors such as smoking and contact with school-aged children $^{[14,15]}$ were not looked into the present study. This is a single-center-based prospective observational study, and hence, causal pathways are difficult to establish. Moreover, 
lung function tests for infants were not done and 36 patients were lost to follow-up.

\section{ConcLusion}

Nearly one-sixth of all preterm neonates treated in our unit required readmissions due to respiratory complaints during infancy. The neonatal risk factors associated with this were gestational age $<32$ weeks, birth weight $<1500$ g, APGAR score $<7$ at $5 \mathrm{~min}$, need for surfactant therapy at birth, presence of hemodynamically significant PDA, and need for respiratory support at birth. Preventive measures directed at these factors may improve long-term respiratory outcomes in this group of neonates.

\section{Financial support and sponsorship}

Nil.

\section{Conflicts of interest}

There are no conflicts of interest.

\section{References}

1. Beck S, Wojdyla D, Say L, Betran AP, Merialdi M, Requejo JH, et al. The worldwide incidence of preterm birth: A systematic review of maternal mortality and morbidity. Bull World Health Organ 2010;88:31-8.

2. Blencowe H, Cousens S, Oestergaard MZ, Chou D, Moller AB, Narwal R, et al. National, regional, and worldwide estimates of preterm birth rates in the year 2010 with time trends since 1990 for selected countries: A systematic analysis and implications. Lancet 2012;379:2162-72.

3. Jobe AH. The new bronchopulmonary dysplasia. Curr Opin Pediatr 2011;23:167-72.

4. Cheraghi M, Dadgarinejad A, Salvi S. A cross-sectional study to find prevalence and risk factors for childhood asthma in Pune City, India. ISRN Public Health. Hindawi 2012;2012:1-8.

5. Fenton TR, Kim JH. A systematic review and meta-analysis to revise the Fenton growth chart for preterm infants. BMC Pediatr 2013;13:59.

6. Eichenwald EC, Committee on Fetus and Newborn, American Academy of Pediatrics COFA. Apnea of Prematurity. Pediatrics. 2016;137:e20153757.

7. Warren JB, Anderson JM. Core concepts: Respiratory distress syndrome. Neoreviews 2009;10:e351-61.

8. Sepsis in the Newborn. Available from: https://www.newbornwhocc. org/2014_pdf/Neonatal sepsis 2014.pdf [Last accessed on 2018 Jun 04].

9. Lakshminrusimha S, Keszler M. Persistent pulmonary hypertension of the newborn. Neoreviews 2015;16:e680-92.

10. Fanaroff AA. Meconium aspiration syndrome: Historical aspects. J Perinatol 2008;28 Suppl 3:S3-7.

11. Zahr RA, Ashfaq A, Marron-Corwin M. Neonatal pulmonary hemorrhage. Neoreviews 2012;13:e302-6.

12. Jobe AH. The New BPD. Neoreviews 2006;7:e531-45.

13. American Academy of Pediatrics Subcommittee on Diagnosis and Management of Bronchiolitis. Diagnosis and Management of Bronchiolitis. Pediatrics 2006;118:1774-93. Available from: http:// www.ncbi.nlm.nih.gov/pubmed/17015575. [Last accessed Won 2018 Jun 09].

14. Pérez-Yarza EG, Moreno-Galdó A, Ramilo O, Rubí T, Escribano A, Torres A, et al. Risk factors for bronchiolitis, recurrent wheezing, and related hospitalization in preterm infants during the first year of life. Pediatr Allergy Immunol 2015;26:797-804.

15. de Mello RR, Dutra MV, Ramos JR, Daltro P, Boechat M, Lopes JM. Neonatal risk factors for respiratory morbidity during the first year of life among premature infants. Sao Paulo Med J 2006;124:77-84.

16. Pramana IA, Latzin P, Schlapbach LJ, Hafen G, Kuehni CE, Nelle M, et al. Respiratory symptoms in preterm infants: Burden of disease in the first year of life. Eur J Med Res 2011;16:223-30.

17. Peacock JL, Lo JW, D'Costa W, Calvert S, Marlow N, Greenough A. Respiratory morbidity at follow-up of small-for-gestational-age infants born very prematurely. Pediatr Res 2013;73:457-63.

18. Been JV, Lugtenberg MJ, Smets E, van Schayck CP, Kramer BW, Mommers M, et al. Preterm birth and childhood wheezing disorders: A systematic review and meta-analysis. PLoS Med 2014;11:e1001596.

19. Kotecha SJ, Edwards MO, Watkins WJ, Henderson AJ, Paranjothy S, Dunstan FD, et al. Effect of preterm birth on later FEV1: A systematic review and meta-analysis. Thorax 2013;68:760-6.

20. Hong T, Bolisetty S, Bajuk B, Abdel-Latif M, Oei J, Jaffe A, et al. A population study of respiratory rehospitalisation in very preterm infants in the first 3 years of life. J Paediatr Child Health 2016;52:715-21.

21. Lamarche-Vadel A, Blondel B, Truffer P, Burguet A, Cambonie G, Selton $\mathrm{D}$, et al. Re-hospitalization in infants younger than 29 weeks' gestation in the EPIPAGE cohort. Acta Paediatr 2004;93:1340-5.

22. Doyle LW, Ford G, Davis N. Health and hospitalistions after discharge in extremely low birth weight infants. Semin Neonatol 2003;8:137-45.

23. O'Callaghan MJ, Burns Y, Gray P, Harvey JM, Mohay HI, Rogers Y, et al. Extremely low birth weight and control infants at 2 years corrected age: A comparison of intellectual abilities, motor performance, growth and health. Early Hum Dev 1995;40:115-28.

24. Ralser E, Mueller W, Haberland C, Fink FM, Gutenberger KH, Strobl R, et al. Rehospitalization in the first 2 years of life in children born preterm. Acta Paediatr 2012;101:e1-5.

25. Kotecha SJ, Watkins WJ, Paranjothy S, Dunstan FD, Henderson AJ, Kotecha S. Effect of late preterm birth on longitudinal lung spirometry in school age children and adolescents. Thorax 2012;67:54-61.

26. Oddy WH, Sly PD, de Klerk NH, Landau LI, Kendall GE, Holt PG, et al. Breast feeding and respiratory morbidity in infancy: A birth cohort study. Arch Dis Child 2003;88:224-8.

27. Kaur A, Singh K, Pannu MS, Singh P, Sehgal N, Kaur R. The effect of exclusive breastfeeding on hospital stay and morbidity due to various diseases in infants under 6 months of age: A prospective observational study. Int J Pediatr 2016;3:1-6.

28. Tromp I, Kiefte-de Jong J, Raat H, Jaddoe V, Franco O, Hofman A, et al. Breastfeeding and the risk of respiratory tract infections after infancy: The Generation R Study. PLoS One 2017;12:e172763. 